\title{
On-line Computation of a Local Attainable Moment Set for Reusable Launch Vehicles*
}

\author{
A. S. Hodcl ${ }^{\dagger}$ \\ Yuri B. Shtcsscl ${ }^{\ddagger}$ \\ Submitted for possible publication in the 2002 AIAA G.I\&C Conference
}

\section{Extended Abstract}

Problem description Traditional attitude control design of rcusable launch vchicles involves independent design of autopilot and control allocation modules [SBB99], [SK97], [SHJ00], [PS00], [Hod00]. Unfortunatcly, this results in the potential for overly aggressive commands in the autopilot resulting in a loss of performance duc to actuator saturation, particularly if the autopilot may suffer from integrator wind-up [HH01]. This unfortunate situation can arisc from, c.g., actuator position limits that require that the actuator command vector $\delta_{c}(t) \in \Delta$ wherc $\Delta$ is the set of fcasible actuator commands defincd by

$$
\Delta \triangleq\left\{\delta: \delta_{-} \leq \delta \leq \delta_{+}\right\}
$$

where $\delta_{-}$and $\delta_{+}$are minimum and maximum position commands, respectivcly. Control allocation is limited by the attainable moment set $\mathcal{T}$ [BD95], [Dur93], [Dur99], defincd as

$$
\mathcal{T}=\{\tau: \exists \delta \in \Delta \text { and } G \delta=\tau\}
$$

where $G$ is the current Jacobian (control derivatives) matrix from the vehicle actuator condition vectort $\delta$ to the vehicle body torques $\tau_{b}$

$$
G \triangleq \frac{\partial \tau_{\iota}}{\partial \delta}
$$

On-line calculation of the cntirc attainable moment set $\mathcal{T}$ is not a practical option for the following rcasons:

1. Actuator modcls (acrodynamic) arc approximatc at best.

2. Actuator failure will significantly modify the attainable moment set $\mathcal{T}$.

We propose instcad to calculate a point-wise "snapshot" of $\mathcal{T}$ as shown in Figurc 1. Given a torque command $\tau_{c}$ we compute a local attainable moment set $\mathcal{T}\left(\tau_{c}\right)$ detcrminining the maximum and minimum torque limits in cach channcl ( $x=$ roll, $y=$ pitch, $z=$ yaw) while holding the other torque

\footnotetext{
-This work was supported in part by NASA contract NAS8-01105.

ta.s hodel Ceng. auburn.edu, Dept. Elect. \& Comp. Eng., 200 Broun Hall, Auburn University, Auburn, AL 36849-5201, corresponding author.

tDepartment of Electrical and Computer Engineering, University of Alabama at Huntsville.
} 


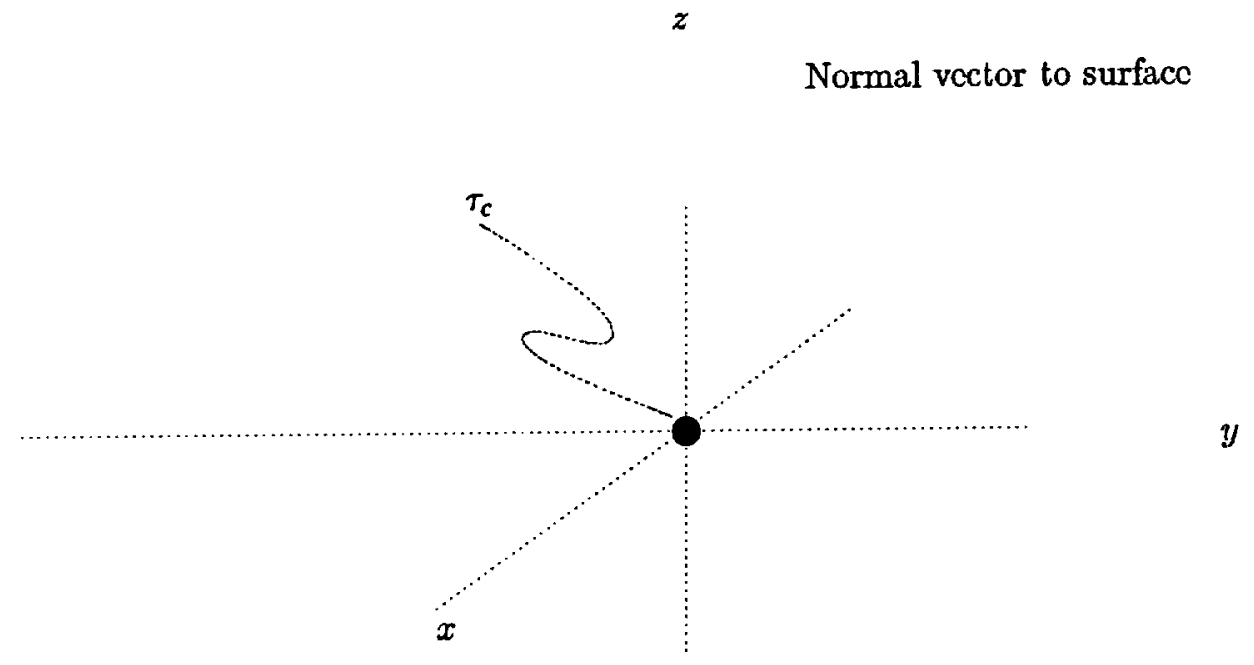

normal vector to surfacc

Figure 1: Attainable moment sct snapshot

values constant. The dimensions of this local attainable moment set can be calculated by a lincar programming problem, c.g., given the current system Jacobian matrix $G$,

$$
\begin{aligned}
\tau_{x, \max }= & \arg \max _{\delta}\left[\begin{array}{lll}
1 & 0 & 0
\end{array}\right] G \delta \\
& \text { subject to } \delta \in \Delta,\left[\begin{array}{lll}
0 & 1 & 0 \\
0 & 0 & 1
\end{array}\right] G \delta=\left[\begin{array}{lll}
0 & 1 & 0 \\
0 & 0 & 1
\end{array}\right] \tau_{c}
\end{aligned}
$$

These torque limits may be of use in two sccnarios:

1. in communicating ovcrall actuator torque limits to the autopilot and autocommander so that autopilot and/or guidance commands may be appropriatcly adjusted, and

2. in flight scenarios where control allocation is required to divide torque commands a primary sct of actuators (c.g, acrosurfaces) and a sccondary backup set of actuators (c.g., reaction thrustcrs).

Torque limits computation and linear programming The computation of the local attainable moment sct can be posed as a sct of six lincar programming problems

$$
\begin{aligned}
\max _{x} J(x) & J(x)=c^{T} x \\
\text { subject to } & A x=b \\
& x^{-} \leq x \leq x^{+}
\end{aligned}
$$


wherc $c^{T}$ and $A$ are construct from appropriate rows of the Jacobian matrix $G$ and the vector $b$ is the sct of "pinned" torques from the current (fcasible) torque command $\tau_{c}$. (If $\tau_{c}$ is infcasible then torque limits $\max J(x)$ can be computed by locating the vertex of the feasible set that minimizes the crror $A x=b$ [Luc84].) Standard codes ${ }^{1}$ available for the lincar programming problem such as dsplp and lp_solve are inappropriatc for this problem, sincc

1. Thesc codes are design for large sparse problems, where as our $A$ matrix is dense and we have vcry fow unknowns - at most 10 or 20.

2. These algorithms can require scveral itcrations to converge to an optimal solution, where as we requirc fast opcration (low computational overhead).

3. Our problem does not change too much from onc time-step to the next (systcm Jacobians do not change much over onc sampling period), so our method should make use of carlicr solutions.

4. Further, our problem docs not requirc an cxact optimal solution - just a good approximation.

We therefore propose the use of a limitcd-itcration simplex method LP solution that uses results (active constraint set) of the previous itcration to computc initial values for the next itcration. Expcrience indicates that two simplex itcrations is sufficient for adequate performance, and so our method requires the inversion of at most $242 \times 2$ matrices ( 2 for cach limit, 2 limits per axis).

We show preliminary results of our method in Figure 2. The routine lpsolve is a full simplex LP solver that exits upon convergence or detection of an infeasible problem (notice time spike at $t \approx 13 \mathrm{sec}$ ). The routine lpIter is an implementation of our fast LP solver. Both lpsolve and lpIter have an outcrmost $\mathrm{m}$-filc script that is uscd to call a C-code implementation of our fast itcration. dmTrqLim is a full C-code translation of 1 pI ter that is included for comparison. Obscrve that, except when the input torque command is infcasible, lpIter closcly tracks that achicvable torque limits cven though it is limited to at most two simplex itcrations per time stcp. This cxample was run with only 6 simulated actuators: similar results werc obtaincd with much larger numbers of actuators in other simulation tests.

These torque limits can then be used to adjust autopilot control parameters on-line so that the autopilot can respond appropriatcly to cither saturations or permancnt failures. Onc potential method for using torque limits is presented cxplicitly in [SBB99]. We arc investigating the use of this method in closed-loop control simulations of the X-33 launch vchicle.

\section{References}

[BD95] Kenncth A. Bordignon and Waync C. Durham. Closcd-form solutions to constraincd control allocation problcm. Joumal of Guidancc, Control, and Dynamics, 18(5):10001007, Scptcmber-Octobcr 1995.

[Dur93] Waync C. Durham. Constraincd control allocation. Journal of Guidance, Control, and Dynamics, 16(4):717-725, August 1993.

\footnotetext{
${ }^{1}$ search on ww' netlib.org or on google for keywords "linear programming")
} 

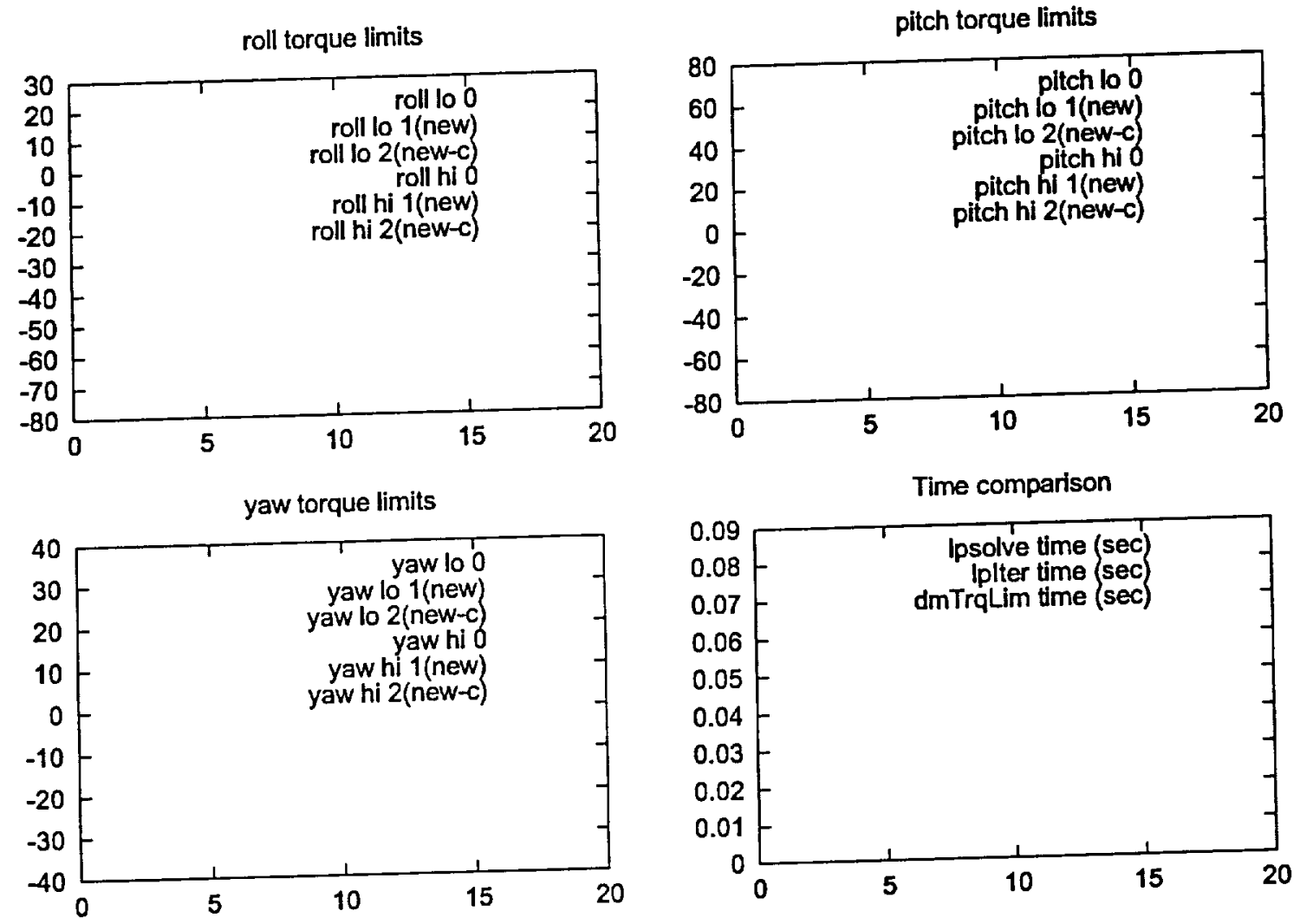

Figurc 2: Preliminary test results for fast computation of the local attainable moment set. Plant Jacobians werc made to vary sinusoidally. An artificial failure (zero cffectivencss) was simulated at $t=10$ scc. Simulation cxperiments were performed with C-code integrated into Octave on a 450 $\mathrm{MHz}$ Macintosh running Ycllow Dog Linux v 2.0.

[Dur99] Waync C. Durham. Efficicnt, ncar-optimal control allocation. Journal of Guidance, 22(2):369-372, 1999.

[HH01] A. Scottcdward Hodel and Charles E. Hall. Variable structurc pid control to prevent intcgrator windup. IEEE Trans. Indust. Elect., 48(2):442-451, April 2001.

[Hod00] A. S. Hodcl. Robust inversion and data compression in control allocation. In Proccedings of AIAA Guidance, Navigation, and Control Conference and Exhibit, Denver, Colorado, August 14-17 2000. Amcrican Institute of Acronautics and Astronautics. Papcr AIAA2000-4154.

[Luc84] D. G. Lucnbergcr. Introduction to Lincar and Nonlinear Programming. Addison-Weslcy, Reading, MA, 2nd cdition, 1984. 
[PS00] Anthony B. Page and Marc L. Stcnberg. A closcd-loop comparison of control allocation methods. In Proccedings of AIAA Guidancc, Navigation, and Control Conference and Exhibit, Denver, Colorado, August 14-17 2000. Amcrican Institutc of Acronautics and Astronautics. Papcr AIAA-2000-4538.

[SBB99] Y. Shtcsscl, J. Buffington, and S. Banda. Multiple time scale flight control using reconfigurable sliding modes. AIAA Journal on Guidance, Control, and Dynamics, 22(6):873-883, 1999.

[SHJ00] Y. Shtcsscl, C. E. Hall, and M. Jackson. Rcusable launch vchiclc control in multiplc time scalc sliding modes. In Proceedings of AIAA Guidance, Navigation, and Control Conference, number AIAA-2000-4155, Denver, Co, August 14-17 2000. AIAA.

[SK97] Yuri Shtcsscl and Don Krupp. Reusable launch vehicle trajectory control in sliding modes. In Proceedings of the American Control Conference, pages 2557-2561, Albuquerque, New Mexico, Junc 1997. 